\title{
REVIEW OF SCALED PENNING H' SURFACE PLASMA SOURCE WITH SLIT EMITTERS FOR HIGH DUTY FACTOR LINACS *
}

\author{
J. D. Sherman, W. B. Ingalls, G. Rouleau, and H. V. Smith, Jr., LANL, Los Alamos, NM, USA \\ J. Thomason and R. Sidlow, ISIS Facility, Rutherford Appleton Laboratory, Oxfordshire, UK \\ R. Ferdinand and R. Gobin, CEA-Saclay, Gif sur Yvette Cedex, France
}

\begin{abstract}
The Penning $\mathrm{H}^{-}$surface plasma source (SPS) is used at Rutherford Appleton Laboratory (RAL) to provide required $\mathrm{H}^{-}$beams for charge-exchange injection into the $800-\mathrm{MeV}$ proton synchrotron on the ISIS spallation neutron source. The RAL source is based on the first $\mathrm{H}^{-}$ Penning SPS operated at Los Alamos. Since the original technology exchange, Los Alamos has developed scaledup versions of the Penning $\mathrm{H}^{-}$SPS with the goal of extending the $\mathrm{H}^{-}$beam duty factor (df) while maintaining high beam brightness. A $250-\mathrm{mA} \mathrm{H}^{-}$beam with rms normalized emittance of $<0.3(\pi \mathrm{mm}-\mathrm{mrad})$ in both transverse planes has been extracted from a $4 \mathrm{X}$ scaled Penning source at a discharge $\mathrm{df}$ of $0.5 \%$. Using discharge scaling laws and the $250-\mathrm{mA}$ results, it is predicted that a $4 \mathrm{X}$ Penning $\mathrm{H}^{-}$SPS with a slit emitter would be capable of producing $>100-\mathrm{mA}$, low emittance $\mathrm{H}^{-}$beams in the $5 \%$ df range.
\end{abstract}

\section{INTRODUCTION}

Proposed accelerator drivers for short and long pulse spallation targets for neutron beam production place demanding requirements on the injector section[1]. For the short-pulsed mode the European Spallation Source (ESS) proposes $100-\mathrm{mA} \mathrm{H}^{-}$beams in a linac operating at $5 \%$ df $(50 \mathrm{~Hz}, 1.0 \mathrm{~ms})$ [2]. The purpose of this paper is to review the dimensionally and discharge-power scaled $\mathrm{H}^{-}$ Penning surface-plasma sources (SPS) using slit emitters in terms of high $\mathrm{H}^{-}$current and comparatively long $\mathrm{df}$ requirements (5\%). Previously published work on the $4 \mathrm{X}$ scaled Penning source at Los Alamos showed that 250$\mathrm{mA} \mathrm{H}$ current could be extracted at $29 \mathrm{keV}$ from a slit emitter[3] at $0.5 \%$ df $(5 \mathrm{~Hz}, 1 \mathrm{~ms})$. This attractive beam current was somewhat overshadowed by asymmetric emittances of $0.15 \times 0.29$ ( $\pi \mathrm{mm}-\mathrm{mrad}) \mathrm{rms}$, normalized, which was thought to be difficult to match to a radiofrequency quadrupole (RFQ). However, over the past ten years RFQ design activities have shown that RFQs with a beam acceptance of $0.3(\pi \mathrm{mm}-\mathrm{mrad})$ are possible while still maintaining a high-quality linac design[2]. Further, design studies of matching beams with asymmetric emittances in the transverse planes to an RFQ using solenoid-lens[4] and quadrupole magnet focusing[5] lowenergy beam transport (LEBT) systems indicate successful matches are possible. Thus there is a renewed interest and acceptance of the use of slit beams as injectors for RFQs.

\footnotetext{
*jsherman@lanl.gov
}

\section{PENNING H' SPS SCALING LAWS AND HISTORICAL PERSPECTIVE}

Application of discharge scaling laws to the SPS $\mathrm{H}^{-}$ Penning discharge for scaling source dimensional parameters up by the factor 4 in two of the three spatial dimensions has led to the source equations summarized in Table 1. Here the subscript $4 \mathrm{X}$ refers to the Penning SPS $\mathrm{H}^{-}$source with a cathode area four times the $1 \mathrm{X}$ source. These equations are based on the general theory of surface $\mathrm{H}^{-}$production[6] and discharge scaling laws contained in standard texts [7] on discharge physics. The prospect for increased $4 \mathrm{X}$ source $\mathrm{df}\left(\mathrm{df}_{4 \mathrm{X}}\right)$ is related to the decreased

Table 1. 4X and $1 \mathrm{X} \mathrm{H}^{-}$source parameters.

\begin{tabular}{|c|l|c|}
\hline ENTRY & \multicolumn{1}{|c|}{$\begin{array}{c}\text { SOURCE } \\
\text { PARAMETER }\end{array}$} & $\begin{array}{c}\text { 4X - 1X } \\
\text { RELATIONSHIP }\end{array}$ \\
\hline 1 & Discharge pressure & $\mathrm{P}_{4 \mathrm{X}}=\mathrm{P}_{1 \mathrm{X}} / 4$ \\
\hline 2 & $\mathrm{H}_{2}$ gas mass flow & $\mathrm{Q}_{4 \mathrm{X}}=\mathrm{Q}_{1 \mathrm{X}}$ \\
\hline 3 & Disch. magnetic field & $\mathrm{B}_{4 \mathrm{X}}=\mathrm{B}_{1 \mathrm{X}} / 4$ \\
\hline 4 & Discharge Voltage & $\mathrm{V}_{4 \mathrm{X}}=\mathrm{V}_{1 \mathrm{X}}$ \\
\hline 5 & Discharge Current & $\mathrm{I}_{4 \mathrm{X}}=\mathrm{I}_{1 \mathrm{X}}$ \\
\hline 6 & Cathode area & $\mathrm{CA}_{4 \mathrm{X}}=4 \mathrm{CA} \mathrm{A}_{1 \mathrm{X}}$ \\
\hline 7 & Cathode power load & $\mathrm{F}_{4 \mathrm{X}}=\mathrm{F}_{1 \mathrm{X}} / 4$ \\
\hline 8 & Disch. current densities & $\mathrm{J}_{4 \mathrm{X}}=\mathrm{J}_{1 \mathrm{X}} / 4$ \\
\hline 9 & Emission area & $\mathrm{EA}_{4 \mathrm{X}}=4 \mathrm{E} \mathrm{A}_{1 \mathrm{X}}$ \\
\hline 10 & $\mathrm{H}^{-}$beam current & $\mathrm{i}_{4 \mathrm{X}}=\mathrm{i}_{1 \mathrm{X}}$ \\
\hline 11 & $\mathrm{H}^{-}$beam current density & $\mathrm{j}_{4 \mathrm{X}}=\mathrm{j}_{1 \mathrm{X}} / 4$ \\
\hline 12 & $\mathrm{H}^{-}$beam production eff. & $\xi_{4 \mathrm{X}}=\xi_{1 \mathrm{X}}$ \\
\hline
\end{tabular}

cathode power load, $\mathrm{F}_{4 \mathrm{X}}$. A fundamental limit to the stability of the Penning discharge and hence stable $\mathrm{H}^{-}$ beam formation is the cesium equilibrium concentration in the discharge volume and cathode surfaces[8]. The pulsed temperature rise of a surface[9] is given by $\Delta \mathrm{T}_{\mathrm{nX}}=$ $2 \mathrm{~F}_{\mathrm{nX}} \operatorname{sqrt}(\Delta \mathrm{t} /(\pi \mathrm{K} \rho \mathrm{C}))$ where $\Delta \mathrm{T}_{\mathrm{nX}}=$ pulsed temperature rise, $\quad F_{n X}=$ cathode power $\operatorname{load}\left(\mathrm{W} / \mathrm{cm}^{2}\right)=$ $\mathrm{V}_{\mathrm{nX}} \mathrm{I}_{\mathrm{nX}} /\left(3 \mathrm{CA}_{\mathrm{nX}}\right), \Delta \mathrm{t}=$ pulse length(s), $\mathrm{K}=$ thermal conductivity constant $\left(\mathrm{W} / \mathrm{cm}^{\circ} \mathrm{C}\right), \rho=\operatorname{density}\left(\mathrm{gm} / \mathrm{cm}^{3}\right)$, and $\mathrm{C}=$ specific heat $\left(\mathrm{J}_{\mathrm{gm}}{ }^{\circ} \mathrm{C}\right)$. The index $\mathrm{n}$ equals one $(1 \mathrm{X})$ or four $(4 \mathrm{X})$ for the discussion in this paper. The factor $(1 / 3)$ in $\mathrm{F}_{\mathrm{nX}}$ comes from equipartitioning the total discharge power to each of the two cathodes and to the anode. The fundamental hypothesis of the $4 \mathrm{X}$ technology is that by decreasing the pulsed surface temperature rise the proper cesium balance can be maintained at longer duty factors. The beam current density defined as entry 11 in Table 1 is defined as $j_{n X}=i_{n X} / E A_{n X}$. The emission area $E A_{n X}$ is equal to the emission slit length $\left(\mathrm{y}_{\mathrm{nX}}\right)$ multiplied by its 
width $\left(\mathrm{x}_{\mathrm{nX}}\right)$ - see Table 2 . The $\mathrm{x}_{4 \mathrm{X}}=2.8 \mathrm{~mm}$ is somewhat larger than the value of $2.0 \mathrm{~mm}$ desired from the factor $4 \mathrm{X}$ scaling, and was the result of a fabrication error.

Table 2 shows dimensional comparisons of the the RAL source, LANL $1 \mathrm{X}$ source, and the $4 \mathrm{X}$ source as developed

Table 2. Comparison of the LANL and RAL 1X SPS dimensions with the $4 \mathrm{X}$ source.

\begin{tabular}{|c|c|c|c|}
\hline Component & RAL 1X & LANL 1X & LANL 4X \\
\hline Ion Source & 5 & 4.3 & 17 \\
\hline $\begin{array}{c}\text { L (mm) } \\
\text { Cath-cath gap }\end{array}$ & 2 & 3 & 17 \\
\hline $\begin{array}{c}\text { W (mm) } \\
\text { Discharge depth }\end{array}$ & 10 & 12 & 16 \\
\hline $\begin{array}{c}\text { T (mm) } \\
\text { Disch. length }\end{array}$ & 10 & 10 & 11.4 \\
\hline Emission slit \\
$\begin{array}{c}\text { y (mm) } \\
\text { Perp. to B field }\end{array}$ & 0.6 & 0.5 & 2.8 \\
\hline $\begin{array}{c}\text { x (mm) } \\
\text { Parall. to B field }\end{array}$ & & & \\
\hline
\end{tabular}

at LANL. It is noted the LANL and RAL Penning sources have nearly identical dimensions, reflecting the earlier technology exchange between the two labs[10]. Thus, both the LANL $1 \mathrm{X}$ and RAL sources may be referred to as $1 \mathrm{X}$ sources. Further definition of the ion source and emission slit components are described in Fig. 2 of ref.[3].

Figure 1 shows the measured $F_{n X}$ for the $1 X$ and $4 X$ sources plotted versus performance publication date. The RAL 1X source data are from [11,12], and the LANL 1X source data are from[13,14]. The $\mathrm{i}_{\mathrm{nX}}$ for the various sources are indicated. An observation for the $1 \mathrm{X}$ sources is that $\mathrm{H}^{-}$current is inversely rated to the duty factor with the product of $\left(\mathrm{i}_{1 \mathrm{X}}\right)\left(\mathrm{df}_{1 \mathrm{X}}\right)=80(\mathrm{~mA} \%)$ being nearly

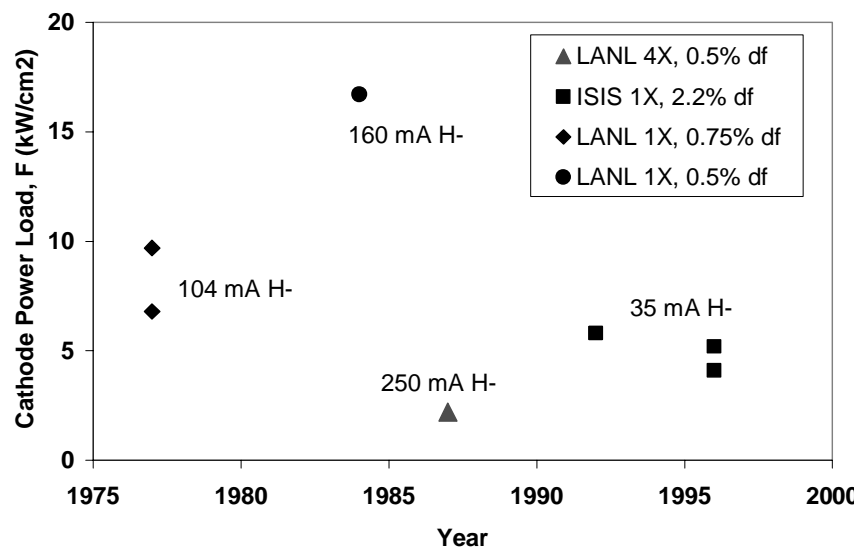

Fig. 1. Measured cathode power loads for the $1 \mathrm{X}$ and $4 \mathrm{X}$ scaled $\mathrm{H}^{-}$Penning SPS.

constant. The exploratory experiment completed for the $4 \mathrm{X}$ slit emitter which produced $250 \mathrm{~mA} \mathrm{H}^{-}$did not probe the $\mathrm{df}_{4 \mathrm{X}}$ limit. However, $4 \mathrm{X}$ source has been operated at $2.3 \% \mathrm{df}_{4 \mathrm{X}}$ with circular emission apertures with $\mathrm{F}_{4 \mathrm{X}}=$ $2.5 \mathrm{~kW} / \mathrm{cm}^{2}$ [3], slightly more than the $2.2 \mathrm{~kW} / \mathrm{cm}^{2}$ shown in Fig. 1. It is readily apparent from previous $4 \mathrm{X}$ circular aperture measurements and the data contained in Fig. 1 that the $4 \mathrm{X}$ slit source $\mathrm{df}_{4 \mathrm{X}}$ could be increased.

Another useful factor to consider in scaled $\mathrm{H}^{-}$Penning SPS technology is the $\mathrm{H}^{-}$beam production efficiency $\xi_{\mathrm{nX}}$ shown as entry 12 in Table 1[3]. The definition of $\xi_{\mathrm{nX}}=$ $\mathrm{j}_{\mathrm{nX}} / \mathrm{F}_{\mathrm{nX}}$, thus $\xi_{4 \mathrm{X}}=\xi_{1 \mathrm{X}}$ is expected from the scaling laws.

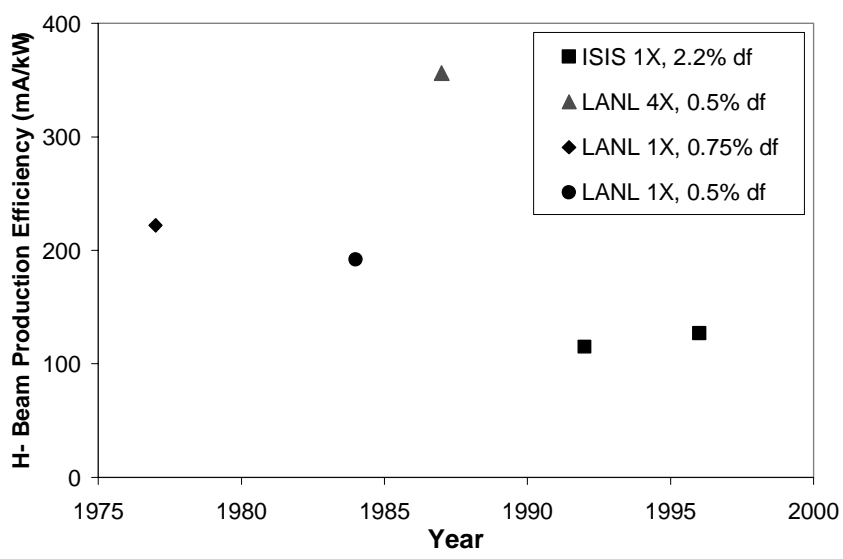

Fig. 2. H- beam production efficiency for the $1 \mathrm{X}$ and $4 \mathrm{X}$ sources plotted vs data publication year.

The publication data used in Fig. 1 is used to construct Fig. 2, where $\xi_{\mathrm{nX}}$ is plotted vs year for the $1 \mathrm{X}$ and $4 \mathrm{X}$ sources. It is noted that the $4 \mathrm{X}$ source has a beneficial increase of about factor 2 in $\xi_{4 X}$ compared with $\xi_{1 X}$ [3].

\section{4X SCALING LAW RESULTS}

The $250-\mathrm{mA} \mathrm{H}^{-}$beam pulse is shown in Fig. 3. The beam noise of $+/-1 \%$ is compatible with linear accelerator applications. Measured x-y emittance scans at the 250-

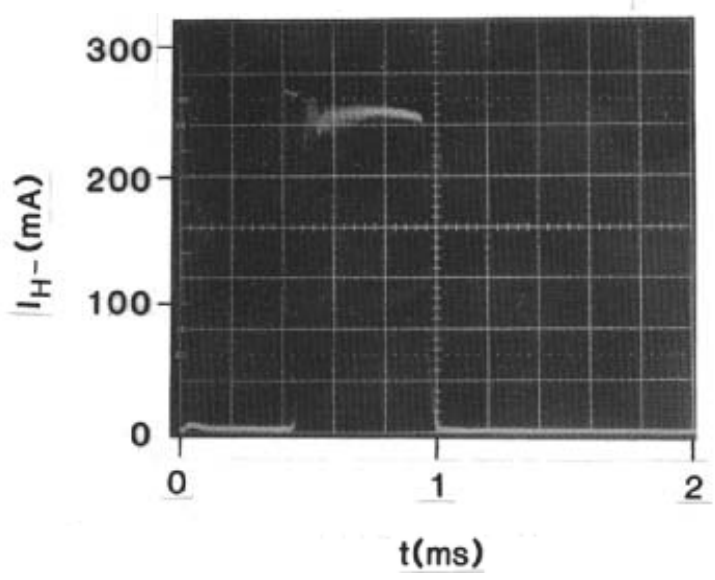

Fig. 3. 250-mA H- beam pulse from the $4 \mathrm{X}$ source.

$\mathrm{mA} \mathrm{H} \mathrm{H}^{-}$current are $\varepsilon_{\mathrm{x}} \mathrm{X} \varepsilon_{\mathrm{y}}=0.15 \mathrm{X} 0.29(\pi \mathrm{mm}-\mathrm{mrad}) \mathrm{rms}$, normalized. These measurements are discussed in [15].

Table 3 summarizes the $1 \mathrm{X}$ to $4 \mathrm{X}$ scaling results for the slit beam. Column 1 gives the ion source parameter, column 2 gives the $1 \mathrm{X}$ actual design and column 3 gives the $4 \mathrm{X}$ design based on the scaling laws of Table 1 . Column 4 shows the actual result for an optimized $4 \mathrm{X}$ 
source, and column 5 shows results for an aggressively cooled 4X cathode operating in the discharge-only mode[16]. There is generally good agreement between column 3 (4X design) and column 4 ( $4 \mathrm{X}$ actual). The discharge depth $\mathrm{W}_{4 \mathrm{X}}$ was increased from 12 to $17 \mathrm{~mm}$ to obtain a quiescent discharge that produces a low-noise beam. To reach the $250-\mathrm{mA} 4 \mathrm{X}$ current, $\mathrm{F}_{4 \mathrm{X}}=2.2$ $\mathrm{kW} / \mathrm{cm}^{2}$ was required, about a factor of two lower than the $4.2 \mathrm{~kW} / \mathrm{cm}^{2}$ scaling law prediction. This reduction results in a factor 2 increase in the $\xi_{4 \mathrm{X}}$ (cf. Fig. 2) compared to that of the $1 \mathrm{X}$ sources. One may expect a factor of 5 increase in the $4 \mathrm{X}$ source $\mathrm{x}$-plane emittance based on the increase of slit width from $0.5 \mathrm{~mm}$ to $2.8 \mathrm{~mm}$, but only a factor of 2.5 emittance increase is observed (0.15 $\pi \mathrm{mm}$-mrad vs. $0.06 \pi \mathrm{mm}-\mathrm{mrad})$.

This paper is concluded by a discussion of the application of the $4 \mathrm{X}$ technology to $100-\mathrm{mA}, 5 \% \mathrm{df}_{4 \mathrm{X}} \mathrm{H}^{-}$ beams. First, from the fifth column of Table 3 the $4 \mathrm{X}$ source has already operated at $6 \% \mathrm{df}_{4 \mathrm{X}}$ at $125 \mathrm{~A}$ of arc discharge current. Thus, to reach nominal $6 \%$ df at 100 $\mathrm{mA} \mathrm{H}{ }^{-}$from the measured $4 \mathrm{X}$ power efficiency in column 4 , only $80 \mathrm{~A}$ of arc discharge current would be required, as $\mathrm{I}_{4 \mathrm{X}}\left(\mathrm{i}_{4 \mathrm{X}}=100 \mathrm{~mA}\right)=(100 \mathrm{~mA} / 250 \mathrm{~mA}) 197 \mathrm{~A}=80 \mathrm{~A}$. This scaling implies that the $\mathrm{H}^{-}$beam production is a linear function of the Penning discharge current. This scaling has been demonstrated from $10^{-2}$ to $10^{2} \mathrm{~A}$ arc current in

Table 3. Experimental results for the application of the scaling laws to the $4 \mathrm{X} \mathrm{H}$ - Penning SPS using slit emitters.

\begin{tabular}{|l|c|c|c|c|}
\hline $\begin{array}{l}\text { ION SOURCE } \\
\text { PARAMETER }\end{array}$ & $\begin{array}{c}\text { 1X } \\
\text { ACTUA } \\
\text { L }\end{array}$ & $\begin{array}{c}\text { 4X } \\
\text { DESI } \\
\text { GN }\end{array}$ & $\begin{array}{c}\text { 4X } \\
\text { ACTU } \\
\text { AL }\end{array}$ & $\begin{array}{c}\text { 4X } \\
\text { DISCH } \\
\text { ONLY }\end{array}$ \\
\hline $\mathrm{L}(\mathrm{mm})$ & $4.3-5$ & 17 & 17 & 17 \\
\hline $\mathrm{W}(\mathrm{mm})$ & $2-3$ & 12 & 17 & 17 \\
\hline $\mathrm{T}(\mathrm{mm})$ & 12 & 16 & 16 & 16 \\
\hline B-field $(\mathrm{G})$ & 2200 & 550 & 460 & 500 \\
\hline Duty factor $(\%)$ & 0.5 & $2-3$ & 0.5 & $6 \%$ \\
\hline Disch. Volt $(\mathrm{V})$ & 100 & 100 & 93 & 115 \\
\hline Disch. Cur. $(\mathrm{A})$ & 180 & 240 & 197 & 125 \\
\hline $\mathrm{H}^{-}$Cur. $(\mathrm{mA})$ & 160 & 160 & 250 & - \\
\hline $\mathrm{j}_{\mathrm{H}^{-}}\left(\mathrm{mA} / \mathrm{cm}^{2}\right)$ & 3200 & 800 & 783 & - \\
\hline $\mathrm{F}_{\mathrm{nX}}\left(\mathrm{kW} / \mathrm{cm}^{2}\right)$ & 16.7 & 4.2 & 2.24 & 1.76 \\
\hline$\xi_{\mathrm{nX}}(\mathrm{mA} / \mathrm{kW})$ & 192 & 192 & 349 & - \\
\hline Emis.(y,x)(mm) & $10,0.5$ & $10,2.0$ & $\mathbf{1 1 . 4 , 2 . 8}$ & \\
\hline $\begin{array}{l}\mathrm{rms} \mathrm{Emit} . \\
(\pi \mathrm{mm}-\mathrm{mrad})\end{array}$ & $0.17(\mathrm{y})$, & & $0.29(\mathrm{y})$, & - \\
\hline
\end{tabular}

the $1 \mathrm{X}$ source[13]. Another observation is that a circular emitter beam on the $4 \mathrm{X}$ source operated at $180 \mathrm{~A}$ discharge with $2.3 \% \mathrm{df}_{4 \mathrm{X}}[3]$. Assuming the product of $\mathrm{i}_{4 \mathrm{X}}$ and discharge $\mathrm{df}_{4 \mathrm{X}}(\%)$ is constant (as observed in the LANL and RAL $1 \mathrm{X}$ sources - see discussion above), one can write $\left(\mathrm{i}_{4 \mathrm{X}}\right)\left(\mathrm{df}_{4 \mathrm{X}}\right)=250 \mathrm{~mA}(180 \mathrm{~A} / 197 \mathrm{~A})(2.3 \%)=$ $525(\mathrm{~mA} \%)$, or at $5 \% \mathrm{df}_{4 \mathrm{X}}$ a $105 \mathrm{~mA} \mathrm{H}^{-}$beam could be obtained. Using the linear $\mathrm{H}^{-}$beam/arc discharge current scaling for the slit beam the $105 \mathrm{~mA} \mathrm{H}^{-}$would require $83 \mathrm{~A}$ of discharge current. These two rather independent scalings indicate order $100 \mathrm{~mA} \mathrm{H}^{-}$beam may be available from the $4 \mathrm{X}$ slit source at $80 \mathrm{~A}$ discharge current for $\mathrm{df}_{4 \mathrm{X}}=$ $5 \%$. If such performance could be demonstrated, the Penning 4X technology could be considered for application to high-power linac drivers[2].

\section{REFERENCES}

[1] G. I. Dimov, "Use of Hydrogen Negative Ions in Particle Accelerators", Rev. Sci. Instrum. 67, (October, 1996), 3393.

[2] R. Duperrier, et. al., "The ESS Front End Associated with the SC Linac", ESS TAC Meeting $\mathrm{n}^{0}$ 1, FZ Juelich, January 7-9, 2002.

[3] H. Vernon Smith, Jr., et. al., " $\mathrm{H}^{-}$and $\mathrm{D}^{-}$Scaling Laws for Penning Surface-Plasma Sources", Rev. Sci. Instrum. 65, (January, 1994), 123.

[4] C. W. Planner, "Matching Unequal Transverse Emittances from an $\mathrm{H}^{-}$Ion Source into a RFQ", Particle Accelerators 48, (1995), 243.

[5] O. R. Sander, et. al., "Transverse Emittance of a 2.0MeV RFQ Beam with High Brightness", IEEE Trans. on Nuclear. Sci., (Oct., 1985), 2588.

[6] Yu I. Belchenko, et. al., "Physical Principles of the Surface Plasma Method for Producing Beams of Negative Ions", in the Proc. of the Symp. on the Prod. and Neutralization of Negative Hydrogen Ions and Beams, Brookhaven New York, BNL 50727, (Sept., 1977), 79.

[7] A. von Engel, Ionized Gases, Second Edition, Oxford University Press (1965), 288.

[8] G. E. Derevyankin and Vadim Dudnikov, "Production of High-Brightness $\mathrm{H}^{-}$Beams in Surface Plasma Sources", in the Proc. Symp. on the Prod. and Neut. of Negative Hydrogen Ions and Beams, Brookhaven New York, AIP Conference Proceedings No. 111, (1983), 376.

[9] H. S. Carslaw and J. C. Jaeger, Conduction of Heat in Solids, 2nd Edition, Oxford University Press (1959), 401.

[10] P. E. Gear and R Sidlow, Proc. of the Second International Conference on Low-Energy Ion Beams, Institute of Physics Conf. Series No 54(1980), 284.

[11] R Sidlow, et. al., "Performance of the Penning H- Ion Source at ISIS", in the Proc. of the Third European PAC, Berlin, Editions Frontieres, (March, 1992), 1005.

[12] R. Sidlow, et. al., "Operational Experience of Penning $\mathrm{H}^{-}$Ion Sources at ISIS", in the Proc. of the Fifth European PAC, Sitges (Barcelona), Institiute of Physics Publishing, (June, 1996), 1525.

[13] Paul W. Allison, "A Direct Extraction $\mathrm{H}^{-}$Ion Source", IEEE Transactions on Nuclear Science, Vol. NS24, No. 3 (June 1977), 1594.

[14] Paul Allison and Joseph D. Sherman, "Operating Experience with a $100-\mathrm{keV}, 100-\mathrm{mA} \mathrm{H}^{-}$Injector", in the Proc. Symp. on the Prod. and Neut. of Negative Hydrogen Ions and Beams, Brookhaven New York, AIP Conference Proceedings No. 111, (1983), 511.

[15] J. Sherman, et. al., 20 ${ }^{\text {th }}$ ICFA Advanced Beam Dynamics Workshop, Fermilab, Batavia, IL., (April 8-12, 2002), to be published.

[16] H. Vernon Smith, Jr., et. al., "H $\mathrm{H}^{-}$Ion Source with High Duty Factor", in Proc. of the 1987 IEEE Particle Accelerator Conf., (March, 1987), 301. 